\title{
The Vocabulary-Comprehension Relationship across the Disciplines: Implications for Instruction
}

\author{
Janis Harmon ${ }^{1, *}$ and Karen Wood ${ }^{2}$ \\ 1 Department of Interdisciplinary Learning and Teaching, College of Education and Human Development, \\ University of Texas, San Antonio, TX 78249, USA \\ 2 Department of Reading and Elementary Education, University of North Carolina, Charlotte, NC 28223, USA; \\ kdwood@uncc.edu \\ * Correspondence: janis.harmon@utsa.edu
}

Received: 10 June 2018; Accepted: 12 July 2018; Published: 17 July 2018

\begin{abstract}
The main purpose of vocabulary instruction is to enhance and support reading comprehension. This goal spans across the grade levels and different disciplines and is supported by a plethora of research. In recent years, a great deal of needed attention has been finally given to academic vocabulary and disciplinary literacy. To contribute to this body of knowledge, we believe it is critical to examine how the complex relationship between vocabulary and comprehension may be addressed in secondary content area classrooms, given the unique nature of the academic vocabulary students encounter daily in school. This conceptual paper contains the following: (1) definition of academic vocabulary; (2) description of what is known about the vocabulary-comprehension relationship; (3) conceptualization of the intersection of academic vocabulary and the vocabulary-comprehension relationship; and (4) instructional implications emerging from this intersection. Perhaps this conceptualization may provide disciplinary practitioners more insight to help them make decisions regarding vocabulary instruction.
\end{abstract}

Keywords: academic vocabulary; disciplinary literacy; comprehension

In recent years, a great deal of needed attention has been given to the literacy demands of different content areas (i.e., science, history, mathematics, literature) and how these demands are unique to each subject area. Moving away from a focus on generic strategies promoted under the umbrella of content area literacy, we are now drawing attention to disciplinary literacy with an emphasis on discipline-specific practices employed by the experts in each field of study [1-3]. Disciplinary literacy, in contrast to content area literacy, looks closely at what Fang and Coatoam call "disciplinary habits of mind" [4] (p. 628) in regard to the unique ways, in which experts in different subject areas use to communicate through reading, writing, viewing, visually representing, speaking, and reasoning. As a result, there is increasing evidence that infusing literacy practices tailored to particular disciplines can enhance students' academic achievement [5].

While both content area literacy and disciplinary literacy practices are useful to promote learning in various subject-matter areas [6], one important component in each view is vocabulary. We know that the main purpose of vocabulary instruction is to enhance and support reading comprehension. This goal spans across the grade levels and different disciplines and has been supported by a plethora of research across the decades. In regard to different disciplines, there are two major categories of vocabulary-the specific academic vocabularies associated with particular disciplines as well as general vocabularies shared by the disciplines. To contribute to the understandings of the body of knowledge about vocabulary and comprehension, we believe it is critical to examine how the complex relationship between vocabulary and comprehension may be addressed in secondary content area classrooms, given the unique nature of the academic vocabulary students encounter daily in school. An examination 
of the intersection of the academic vocabulary in the disciplines and the vocabulary-comprehension relationship may provide disciplinary practitioners more insight to inform decision-making regarding vocabulary instruction. We begin by providing an overview of the meaning of academic vocabulary and an explanation of the relationship between vocabulary and comprehension. We then examine the intersection of academic vocabulary and the vocabulary-comprehension relationship and the instructional implications for enhancing learning.

\section{Academic Vocabulary}

Vocabulary growth occurs in both oral and written contexts. Oral contexts appear to support vocabulary more easily, given the natural opportunity for multiple uses and repetition of words as well as the presence of concrete referents [7]. In the case of written contexts, vocabulary acquisition involves engagement in more sophisticated language, especially as students move into the upper grades. In middle schools and high schools, the focus is primarily on reading texts across different subject-matter areas, each of which has its own distinctive language patterns. Nagy and Townsend define this academic language as the "specialized language, both oral and written, of academic settings that facilitate communication and thinking about disciplinary content" [8] (p. 92). In the words of Zwiers, the academic language in each discipline is "the set of words, grammar, and organizational strategies used to describe complex ideas, higher-order thinking processes, and abstract concepts" [9] (p. 20). The complex and multi-dimensional nature of each discipline requires that students learn about the language of each area in order to gain conceptual knowledge in these fields.

Academic vocabulary is a critical component embedded in the language of all disciplines and places challenging demands on all learners. This vocabulary is critically important for disciplinary learning and thinking. Descriptions about academic vocabulary focus on two distinctive categories of words-technical, content-specific terms and general academic vocabulary. As noted by Baumann and Graves [10], scholars label these content-specific terms in different ways, including technical vocabulary and domain-specific words. Regardless of the label, these are terms representing concepts in particular disciplines, such as fossil fuels, greenhouse effect, and atmosphere when learning about global warming.

General academic vocabulary, on the other hand, are generalized terms that appear across different content areas with their meanings sometimes changing depending upon the context. Examples of general academic vocabulary include analyze, market, legend, and grade. McKeown and her colleagues aptly note the importance of general academic vocabulary, especially for second-language learners by stating that "[high frequency general words] provide the foundation upon which the knowledge of rarer words must build. Developing knowledge of academic vocabulary-mid-frequency, high dispersion words preferentially appearing in academic written texts-is particularly important for K-12 vocabulary development and for advanced language learners" [11] (pp. 55-56).

\section{Vocabulary-Comprehension Relationship}

For many decades, we have accumulated well-documented evidence that vocabulary size is a strong predictor of a student's ability to comprehend text $[12,13]$. This strong correlation between vocabulary and comprehension leads to an obvious conclusion that if teachers teach word meanings, students will comprehend better. However, the relationship between vocabulary and comprehension is not that straightforward and is highly complex involving a host of other variables. To explain this relationship, Anderson and Freebody [12] considered three standpoints that they labeled as the instrumental hypothesis, the knowledge hypothesis, and the aptitude hypothesis. Since then, researchers in the field have augmented these explanations to include others, such as the access hypothesis [14], the metalinguistic hypothesis [15], and the reciprocal hypothesis [16]. These explanations do not contradict each other, but rather illustrate the interplay of multiple variables involved in the vocabulary-comprehension relationship [17]. We provide an explanation of each standpoint or hypothesis. 
Instrumental hypothesis. This common sense explanation suggests that learning word meanings influences comprehension, thus leaning more toward a causal connection between vocabulary and comprehension [12]. Stahl [18] points out two implications embedded in this standpoint. First, if knowledge of words can directly enhance comprehension, texts with more challenging words will be more difficult to understand. Another implication is that directly teaching word meanings will improve comprehension. However, Stahl [18] cautions that not all vocabulary instructional methods will influence comprehension. While knowing word meanings is necessary for comprehension to occur, it is not a sufficient explanation by itself to explain the relationship between vocabulary and comprehension [15].

Knowledge hypothesis. Moving away from the direct, causal relationship implied by the instrumental hypothesis, the knowledge hypothesis takes into account the influence of a mediating variable - that of background knowledge. This explanation of the relationship between vocabulary and comprehension illustrates that word meanings are not learned in isolation; rather, they are developed while learning about a new topic. Such contexts allow students to see how words are semantically related to other words [19]. Furthermore, as Nagy states, " ... it is not [the idea of] knowing the meaning of words that causes readers to understand what they read; rather, knowing the meanings of words is an indication of the readers' knowledge of a topic or concept. It is this knowledge that help readers comprehend" [15] (p. 31). Thus, word knowledge is one aspect of topic knowledge needed for comprehension to occur, and learning about a topic provides the opportunity to increase word knowledge [15,18].

Aptitude hypothesis. Similar to the knowledge hypothesis, the aptitude hypothesis also considers a third variable to explain the relationship between vocabulary and comprehension. In this case, verbal ability plays an important role, since students with a high verbal aptitude tend to know more words, and are better able to learn new words, and comprehend what they read [12,17]. Both Sternberg and Powell [20] and Stahl and Nagy [17] expand the aptitude hypothesis in different ways. Sternberg and Powell [20] interpret this hypothesis to include a reader's ability to make inferences. In this way, inferential ability, as a subset of the aptitude hypothesis, has a critical impact on comprehension, especially when readers must infer the meanings of unfamiliar words encountered in texts. Using a different perspective about the aptitude hypothesis, Stahl and Nagy [17] consider metalinguistic aspects of word learning that can impact comprehension. They argue that readers use their knowledge of language as they construct an understanding of what is being read, that is, they use what they know about morphology (e.g., affixes, roots), syntax, figurative language, polysemy (i.e., multiple meanings of some words), and other language cueing systems, all of which relate to the aptitude hypothesis.

Reciprocal hypothesis. Beck, McKeown, and Omanson question "... a are people good comprehenders because they know a lot of words, or do people know a lot of words because they are good comprehenders and in the course of comprehending text, learn a lot of words, or is there some combination of directionality?" [21] (pp. 147-148). To address this question, Stanovich [16] suggests that there is a reciprocal relationship between vocabulary and comprehension, where vocabulary is increased through reading and comprehending and comprehension is enhanced by knowledge of more words. In the words of Stahl and Nagy, "having a bigger vocabulary makes you a better reader, being a better reader makes it possible for you to read more, and reading more gives you a bigger vocabulary" [17] (p. 13).

Access hypothesis. To explain the complex relationship between vocabulary and reading comprehension, Mezynski [14] suggests another dimension called the access hypothesis. Based upon the theoretical work of LaBerge and Samuels [22] concerning automaticity in reading, the access hypothesis indicates that the quick and easy retrieval of word meanings is necessary for comprehension to occur. Thus, readers must know the various aspects of word meanings (e.g., correct nuances of meanings) well enough for easy access and use while reading. 
Each of these explanations helps to illustrate the complexity of the relationship between vocabulary and comprehension in general and do not contradict each other. Furthermore, they offer a way to examine the relationship between academic vocabulary and reading comprehension in different disciplines.

\section{Intersection of Academic Vocabulary and the Vocabulary-Comprehension Relationship}

Teacher beliefs about teaching in general, and specifically about vocabulary learning and instruction, are important across all grade levels and disciplines [23]. One study by Konopak and Williams [19] examines teacher beliefs about vocabulary teaching and learning from the perspective of the relationship between vocabulary and comprehension. Enlightened by this work, we attempt to conceptualize the intersection between the academic vocabulary across subject-matter areas specifically and the vocabulary-comprehension relationship as represented by the aforementioned hypotheses. Perhaps this perspective may provide insights into what vocabulary practices in content area classrooms may enhance reading comprehension. We address each hypothesis or standpoint in light of both technical, content-specific vocabulary and general academic vocabulary.

Instrumental hypothesis. This hypothesis supports the direct teaching of both technical vocabulary and general academic vocabulary. Explicit instruction that provides definitions of words, both technical and general, is an initiating, introductory event that is necessary but not totally sufficient to ensure that students internalize word meanings. Variability in the kinds of content-specific words is one factor that must be considered. Some words lend themselves well to explicit instruction with definitions. For example, a simple definition for words, such as triangle and perimeter in mathematics, may suffice. Direct instruction for some general academic terms may also work for such words and phrases as find the least amount and record your answer. However, other content-specific words need more detailed and integrated instruction for students to internalize these ideas. For example, in keeping with mathematics examples, the more complex concepts of both slope and functions require more detailed and extensive instruction than the use of simple explanations using definitions. Furthermore, particular general academic words also require more in-depth instruction with words and phrases, such as analyze the data, demonstrate your understanding, and relationship to.

Knowledge hypothesis. Conceptual knowledge speaks explicitly to the teaching and learning of disciplinary vocabulary. In the case of content-specific academic vocabulary, building word knowledge is closely related to building conceptual knowledge. As Vacca and his colleagues point out, "Words are labels for concepts. A single concept, however, represents much more than the meaning of a single word. It may take thousands of words to explain a concept" [24] (p. 243). Moving away from the definitional level, a focus on conceptual knowledge acquisition requires that students engage in meaningful, purposeful experiences, both firsthand and vicariously, in order to learn [24].

Conceptual knowledge, in this case of subject-matter knowledge, is part of a reader's prior knowledge. Two types of prior knowledge are important for literacy learning in the disciplines-topic knowledge and domain knowledge, both of which involve academic vocabulary [25-27]. Topic knowledge focuses on the depth of knowledge a student may have about a topic, that is, what background knowledge and experiences the student has acquired about a topic or a concept. If a student has a strong knowledge base about the topic of diabetes, for example, this student will also have the depth of knowledge about the words and terms that are used in talking and writing about this topic (how well the words are known), words and ideas, such as glucose level, insulin, and proper diet. Domain knowledge, on the other hand, represents the breadth of knowledge that readers have about a particular discipline, including not only the breadth of knowledge about vocabulary (the size of word knowledge), but also the language and thinking associated with a given field of study. In other words, domain knowledge can be considered to be general knowledge experts have in a particular field of study [25]. In the diabetes example, domain knowledge would include knowledge about metabolism, how glucose is used as the main source of energy for the body, health problems caused by a great deal of glucose in the blood (e.g., neuropathy, hypertension, ketones), and the use of hemoglobin 
testing for measuring control of diabetes. Specifically in regard to vocabulary knowledge, both topic and domain knowledge illustrate Schmitt's statement that "all aspects of vocabulary knowledge are interrelated" [28] (p. 942).

In addition to the role of vocabulary in conceptual knowledge, it is important to consider academic vocabulary in light of both linguistic and lexical knowledge. From a disciplinary perspective, linguistic knowledge is knowledge of the language used in particular subject-matter areas and knowledge of language differences across disciplines. Linguistic knowledge is the basis, from which students understand how authors frame the ways in which concepts are explained and described in disciplinary texts. This includes such features as syntactic knowledge, nominalization, multiple meanings of similar words, collocational knowledge, and morphological structures [11]. Table 1 provides explanations and examples for some of these particular features in regard to content specific vocabulary and general academic vocabulary.

Table 1. Features of linguistic knowledge in academic language.

\begin{tabular}{|c|c|c|}
\hline Features & $\begin{array}{l}\text { Examples of Content-Specific } \\
\text { Vocabulary }\end{array}$ & $\begin{array}{l}\text { Examples of General Academic } \\
\text { Vocabulary }\end{array}$ \\
\hline $\begin{array}{l}\text { Nominalization } \\
\text { The practice of changing a verb or } \\
\text { adjective into a noun form }\end{array}$ & $\begin{array}{l}\text { Multiply multiplication } \\
\text { Legislate legislation } \\
\text { Extinct extinction }\end{array}$ & $\begin{array}{l}\text { Demonstrate demonstration } \\
\text { Complete completion } \\
\text { Approximate approximation }\end{array}$ \\
\hline $\begin{array}{l}\text { Multiple meanings of similar } \\
\text { words } \\
\text { The same words having different } \\
\text { meanings depending upon the } \\
\text { contexts in which they are used }\end{array}$ & $\begin{array}{l}\text { Fish scales } \\
\text { Balance scales } \\
\text { Worship in a temple } \\
\text { Temple on the side of a face } \\
\text { Major in the army } \\
\text { Major project }\end{array}$ & $\begin{array}{l}\text { Count the numbers } \\
\text { Count a nobleman } \\
\text { List the battles } \\
\text { List-tilting to one side } \\
\text { Place-a particular area } \\
\text { Place-arranging or putting } \\
\text { something down } \\
\text { Fresh produce at the grocery store } \\
\text { Produce a chart for your data }\end{array}$ \\
\hline $\begin{array}{l}\text { Collocational knowledge } \\
\text { Grouping of words that typically } \\
\text { are used together }\end{array}$ & $\begin{array}{l}\text { Chain reaction } \\
\text { Chemical reaction } \\
\text { Blood pressure } \\
\text { Atmospheric pressure } \\
\text { Tectonic plate } \\
\text { Fifth power of six } \\
\text { Square root of nine } \\
\text { Reciprocal of a number } \\
\text { Multiplicative inverse } \\
\text { Greenhouse effect } \\
\text { Supply and demand }\end{array}$ & $\begin{array}{l}\text { Pay tribute to } \\
\text { Major catastrophe } \\
\text { Present with } \\
\text { Important for } \\
\text { Draw a conclusion } \\
\text { Solve the problem } \\
\text { Is produced by }\end{array}$ \\
\hline $\begin{array}{l}\text { Morphological structures } \\
\text { Patterns of words that share the } \\
\text { same meaning and belong to the } \\
\text { same word family }\end{array}$ & $\begin{array}{l}\text { Linear line } \\
\text { Multiplicative multiply } \\
\text { Number numerical } \\
\text { Genes genetics } \\
\text { Colony colonial }\end{array}$ & $\begin{array}{l}\text { Benefit } \\
\text { Beneficial } \\
\text { Compare } \\
\text { Comparative } \\
\text { Represent } \\
\text { Representative } \\
\text { Minimum } \\
\text { minimal }\end{array}$ \\
\hline
\end{tabular}

Aptitude hypothesis. The relationship between vocabulary and comprehension in different disciplines is also influenced by verbal ability. As students read the informational texts that are unique to each content area, they need to be skillful in inferring particular meanings of technical vocabulary as well as the different uses of general academic vocabulary in each discipline of study. For both sets of words, metalinguistic knowledge enables readers to reflect upon and manipulate the special vocabulary and language found in each discipline [15]. Given that all the disciplines have unique and 
significantly different language patterns and terminology [4], it is even more imperative that students acquire the metalinguistic knowledge needed for each field.

Reciprocal hypothesis. The reciprocal relationship between vocabulary and comprehension holds true for reading and understanding in the content areas. When students read more in science, history, and the other disciplines, they are exposed to more of the technical terms as well as the general academic terms used in conveying meaning. The more they read, the more both vocabularies grow and become internalized. The richer their vocabularies become, the better they are able to comprehend different texts and more challenging texts.

Access hypothesis. As in any field of study, the need to internalize word meanings to the point of automatic retrieval is important for comprehension to occur. Again, the richness or depth of word knowledge, as well as the breadth or size of word knowledge about a given topic, aids in the accessibility of word meanings. This accessibility is needed for both content-specific words and general academic vocabulary. Students need multiple opportunities to engage in meaningful, topic-centered contexts and situations, in which both types of disciplinary vocabulary are internalized. Based upon the International Literacy Association's use of the term "literacy" [29], these encounters can include opportunities for students to read, write, speak, listen, view, and visually represent their understandings about specific topics across all disciplines-opportunities that cannot occur without vocabulary and language.

It is important to keep in mind that vocabulary learning is complex and multifaceted. Hence, all of these hypotheses have value and play different roles in helping students attain the necessary vocabulary to be successful in understanding academic texts.

\section{Instructional Implications}

The vocabulary-comprehension hypotheses previously described form the basis of effective vocabulary instructional practices across different disciplines. Structured lesson frameworks typically include teacher preparation, initial explanations, applications, and reinforcement [30]. The support for both content-specific terms and general academic vocabulary can be integrated simultaneously in these instructional formats. Furthermore, each aspect of the lesson draws from what we know about the vocabulary-comprehension connection in disciplinary learning. However, it is important to be mindful that the hypotheses used to explain the vocabulary-comprehension connection can be recursive and overlapping in each segment of a structured lesson.

Teacher preparation. A critical part of any vocabulary lesson is the careful selection of words and phrases that need close attention to support reading. To support comprehension, these words and phrases need to be those that are important for conceptual learning (i.e., technical words) and those that build upon the reader's linguistic knowledge (i.e., general academic vocabulary). Ultimately, the assessment of a student's background knowledge about the terms and phrases is needed for making informed decisions about word selection. The use of the Knowledge Rating Scale [31] for such purposes should include not only the content-specific words but also general academic words and phrases to ensure that all aspects of vocabulary and language are taken into consideration. The knowledge hypothesis supports these efforts to attend to the background knowledge of students.

Initial explanation. The work of Beck and her associates [32] provides important guidelines for introducing new terminology to students. They advocate for the introductions of new words and phrases to include both a context and a "student-friendly" definition that students can understand. This initial step embraces the instrumental hypothesis with a focus on establishing the basic meanings of the terms within a context and not in isolation. The context would especially provide students with a sense of how general academic terms and phrases are used within the language of the text. Again, the variability of both content-specific vocabulary and general academic vocabulary as previously described (i.e., the degree of abstractness of concepts) must be considered in order to provide an explanation that students will understand. From an instrumental standpoint, these initial explanations can be multimodal to include verbal, visual, and virtual tools. The non-linguistic approach of 
using pictures, drawings, charts, graphs and other visual representations has much support in the professional literature for assisting students of all ability levels including English language learners with newly introduced vocabulary $[33,34]$. In addition, digital tools are readily available to help reinforce the student's friendly explanations, such as visuwords.com which shows a graph of related terms and www.visualthesaurus.com which provides an interactive map complete with definitions and pronunciations.

These introductory tasks also reflect the knowledge hypothesis, especially in light of the specific contexts used to build conceptual knowledge. Students must have a working knowledge of the particular contexts used to explain the targeted words and phrases in order to make understandable connections to increase word learning.

Application. Once students have a general understanding of the word meanings, the next instructional step is to have students engage in multiple, meaningful encounters of the words through readings, class discussions, and related activities, in which the conceptually loaded terms and the general academic vocabulary are used. These tasks enable students to make connections of the word usage to a variety of different contexts and situations. However, to be able to connect to the situations, students must have appropriate background knowledge and experiences. Again, the knowledge hypothesis becomes the basis for these learning opportunities. These experiences are even more apparent and necessary across different disciplines. Furthermore, the fact that students need multiple encounters with these varied contexts is supported by the access hypothesis to ensure that the word meanings are internalized deeply, so that students are able to transfer newly acquired learning to other disciplinary-related encounters with the words and phrases. One means for ensuring significant and multiple encounters with words is to pre-teach the key academic vocabulary before reading, ask students to focus on the key words during reading (making notes, drawings, charts) and then revisit the words after the reading [35]. Additional follow-up can take the form of small-group writing activities using the words in the context of the content studied [36].

Reinforcement. As previously mentioned, multiple encounters with newly acquired word meanings not only help students develop breadth and depth of word meanings (knowledge hypothesis), but also reinforce the integration of this new knowledge. Continual revisiting of previously learned word meanings, both content-specific words and general academic vocabulary, is a critical component in the instructional framework. Students need a great deal of exposure to both vocabularies to enable them to use this dynamic knowledge base to learn more unfamiliar words and phrases. The purpose of reinforcement is not only based upon the instrumental, knowledge, and access hypotheses, but also on the aptitude and reciprocal hypotheses. In other words, the more students use newly acquired word meanings in their disciplinary readings, the more they will be exposed to and learn new word meanings, thus building an even greater knowledge from which learning can be continued. This reciprocal nature of word learning occurs through opportunities for students to engage in explanations, explorations, elaborations, and evaluations of various topics and concepts across the disciplines.

\section{Conclusions}

The hypotheses presented in this article suggest important implications for vocabulary instruction [17]. With these theoretical positions as a basis, the potential exists to change the face of vocabulary instruction from merely mentioning, telling, and assigning rote memorization and "look it up in the dictionary" tasks to more meaningful, contextual approaches. To this end, we feel that the single term "vocabulary", which suggests teaching words in isolation be replaced with the broader, multi-dimensional term "vocabulary literacy," which involves making the vocabulary/comprehension connection using all aspects of literacy: reading, writing, listening, speaking, viewing, and visually representing [30]. With this perspective undergirding our teaching of both content-specific and general academic vocabulary terms, students process word meanings more deeply as they actively engage in multi-modal activities designed to promote strategic learning and long-term conceptual understanding. 
Funding: This research received no external funding.

Conflicts of Interest: The author declares no conflict of interest.

\section{References}

1. Conley, M.W. Improving adolescent comprehension. In Handbook of Research on Reading Comprehension, 2nd ed.; Israel, S.E., Ed.; Guilford Press: New York, NY, USA, 2017; pp. 406-427, ISBN 978-1-4625-2888-2.

2. Moje, E.B. Foregrounding the disciplines in secondary literacy teaching and learning: A call for change. J. Adolesc. Adult Lit. 2008, 52, 96-107. [CrossRef]

3. Shanahan, C.; Shanahan, T.; Misischia, C. Analysis of expert readers in three disciplines: History, mathematics, and chemistry. J. Lit. Res. 2011, 43, 393-429. [CrossRef]

4. Fang, Z.; Coatoam, S. Disciplinary literacy: What you want to know about it. J. Adolesc. Adult Lit. 2013, 56, 627-632. [CrossRef]

5. Hynd-Shanahan, C. What does it take? The challenge of disciplinary literacy. J. Adolesc. Adult Lit. 2013, 57, 93-98. [CrossRef]

6. Dunkerly-Bean, J.; Bean, T.W. Missing the savoir for the connaissance: Disciplinary and content area literacy as regimes of truth. J. Lit. Res. 2016, 48, 448-475. [CrossRef]

7. Blachowicz, C.; Fisher, P.; Ogle, D.; Watts-Taffe, S. Teaching Academic Vocabulary K-8: Effective Practices Across the Curriculum; Guilford Press: New York, NY, USA, 2013; ISBN 978-1-4625-1029-0.

8. Nagy, W.E.; Townsend, D. Words as tools: Learning Academic Vocabulary as Language Acquisition. Read. Res. Q. 2012, 47, 91-108. [CrossRef]

9. Zwiers, J. Building Academic Language: Essential Practices for Content Classrooms; Jossey-Bass: San Francisco, CA, USA, 2008; ISBN 978-0-7879-8761-9.

10. Baumann, J.F.; Graves, M.F. What is academic vocabulary? J. Adolesc. Adult Lit. 2010, 54, 4-12. [CrossRef]

11. McKeown, M.G.; Deane, P.D.; Scott, J.A.; Krovetz, R.; Lawless, R.R. Vocabulary Assessment: Buliding Rich Word-Learning Experiences; Guilford Press: New York, NY, USA, 2017; ISBN 978-1-4625-3079-3.

12. Anderson, R.C.; Freebody, P. Vocabulary knowledge. In Comprehension and Teaching: Research Reviews; Guthrie, J., Ed.; International Reading Association: Newark, DE, USA, 1981; pp. 77-117, ISBN 0-87207-943-0.

13. Davis, F.B. Fundamental factors of comprehension in reading. Psychometrika 1944, 9, 185-195. [CrossRef]

14. Mezynski, K. Issues concerning the acquisition of knowledge: Effects of vocabulary training on reading comprehension. Rev. Educ. Res. 1983, 53, 253-279. [CrossRef]

15. Nagy, W.E. Why vocabulary instruction needs to be long-term and comprehensive. In Teaching and Learning Vocabulary: Bringing Research to Practice; Hiebert, E.H., Kamil, M.L., Eds.; Erbaum: Mahwah, NJ, USA, 2005; pp. 27-44, ISBN 0-8058-5286-7.

16. Stanovich, K. Matthew effects in reading: Some consequences of individual differences in the acquisition of literacy. Read. Res. Q. 1986, 21, 360-407. [CrossRef]

17. Stahl, S.; Nagy, W.E. Teaching Word Meanings; Lawrence Erlbaum Associates: Mahwah, NJ, USA, 2006; ISBN 0-8058-4364-7.

18. Stahl, S. Vocabulary Development; Brookline Books: Cambridge, MA, USA, 1999; ISBN 1-57129-072-9.

19. Konopak, B.C.; Williams, N.L. Elementary teachers' beliefs and decisions about vocabulary learning and instruction. In 43rd Yearbook of the National Reading Conference; Kinzer, C.K., Leu, D.J., Eds.; National Reading Conference, Inc.: Chicago, IL, USA, 1994; pp. 485-495, ISSN 0547-8375.

20. Sternberg, R.; Powell, J.S. Comprehending verbal comprehension. Am. Psychol. 1983, 38, 878-893. [CrossRef]

21. Beck, I.L.; McKeown, M.G.; Omanson, R.C. The effects and uses of diverse vocabulary instructional techniques. In The Nature of Vocabulary Acquisition; McKeown, M.G., Curtis, M.E., Eds.; Lawrence Erlbaum Associates, Inc.: Hillsdale NJ, USA, 1987; pp. 147-163, ISBN 0-89859-548-7.

22. LaBerge, D.; Samuels, S.J. Toward a theory of automatic information processing in reading. Cogn. Psychol. 1974, 6, 293-323. [CrossRef]

23. Fang, Z. A review of research on teacher beliefs and practices. Educ. Res. 1996, 38, 47-65. [CrossRef]

24. Vacca, R.T.; Vacca, J.L.; Mraz, M. Content Area Reading: Literacy and Learning Across the Curriculum, 11th ed.; Pearson: Boston, MA, USA, 2014; ISBN 13: 978-0-13-306678-4.

25. Alexander, P.A.; Kulikowich, J.M.; Schulze, S.K. The influence of topic knowledge, domain knowledge, and interest on the comprehension of scientific exposition. Learn. Individ. Differ. 1994, 6, 379-397. [CrossRef] 
26. Buehl, D. Developing Readers in the Academic Disciplines; International Reading Association: Newark, DE, USA, 2011; ISBN 13: 978-0872078451.

27. Jetton, T.L.; Alexander, P.A. Domains, teaching, and literacy. In Adolescent Literacy Research and Practice; Jetton, T.L., Dole, J.A., Eds.; Guilford Press: New York, NY, USA, 2004; pp. 15-39. ISBN 1-59385-021-2.

28. Schmitt, N. Size and depth of vocabulary knowledge: What the research shows. Lang. Learn. 2014, 64, 913-951. [CrossRef]

29. International Literacy Association. Standards for the Preparation of Literacy Professionals 2017; International Literacy Association: Newark, NJ, USA, 2017; ISBN 978-0-87207-379-1.

30. Karen, W.; Wood, K.D.; Harmon, J.; Taylor, D.B. Guidelines for integrating comprehension-based word study in content classrooms. Middle Sch. J. 2011, 42, 57-64.

31. Blachowicz, C.; Fisher, P. Teaching Vocabulary in All Classrooms, 3rd ed.; Pearson Education: Upper Saddle River, NJ, USA, 2006; ISBN 0-13-119803-3.

32. Beck, I.L.; McKeown, M.G.; Kucan, L. Bringing Words to Life: Robust Vocabulary Instruction, 2nd ed.; Guilford Press: New York, NY, USA, 2013; ISBN 978-1-4625-0816-7.

33. Marzano, R.J. The art and science of teaching/Six steps to better vocabulary instruction. Educ. Leadersh. 2009, $67,83-84$.

34. Wood, K.D.; Tinajero, J. Using pictures to teach content to second language learners. Middle Sch. J. 2002, 33, 47-51. [CrossRef]

35. Wood, K.D.; Soares, L.M. How to Integrate Vocabulary, Comprehension and Writing across the Disciplines: Questions from the Classroom; Association of Middle Level Educators: Westerville, OH, USA, 2015.

36. Wood, K.D.; Taylor, D.B.; Stover, K. Smuggling Writing: Getting Students to Write Everyday in Every Content Area, Grades 3-12; Corwin: Thousand Oaks, CA, USA, 2016.

(C) 2018 by the authors. Licensee MDPI, Basel, Switzerland. This article is an open access article distributed under the terms and conditions of the Creative Commons Attribution (CC BY) license (http:/ / creativecommons.org/licenses/by/4.0/). 